Review Article

\title{
Biological Activities of
} $2,3,5,4^{\prime}$-Tetrahydroxystilbene-2-O- $\beta$-D-Glucoside in Antiaging and Antiaging-Related Disease Treatments

\author{
Shuang Ling and Jin-Wen Xu \\ Murad Research Institute for Modernized Chinese Medicine, Shanghai University of Traditional Chinese Medicine, \\ Shanghai 201203, China
}

Correspondence should be addressed to Jin-Wen Xu; jinwen.xu88@gmail.com

Received 17 April 2016; Accepted 29 May 2016

Academic Editor: Ryuichi Morishita

Copyright (C) 2016 S. Ling and J.-W. Xu. This is an open access article distributed under the Creative Commons Attribution License, which permits unrestricted use, distribution, and reproduction in any medium, provided the original work is properly cited.

2,3,5,4'-Tetrahydroxystilbene-2-O- $\beta$-D-glucoside (THSG) is active component of the Chinese medicinal plant Polygonum multiflorum Thunb. (THSG). Pharmacological studies have demonstrated that THSG exhibits numerous biological functions in treating atherosclerosis, lipid metabolism, vascular and cardiac remodeling, vascular fibrosis, cardiac-cerebral ischemia, learning and memory disorders, neuroinflammation, Alzheimer and Parkinson diseases, diabetic complications, hair growth problems, and numerous other conditions. This review focuses on the biological effects of THSG in antiaging and antiaging-related disease treatments and discusses its molecular mechanisms.

\section{Introduction}

Aging is inevitable; it is a progressive, irreversible process that every human will experience in his life. The aging population of the international community brings increasing medical expenses and health care costs. Therefore, prevention and early treatment of aging-related diseases can be effective means of relieving society's burden and living a better life for individuals. There are many theory researches of aging mechanisms. The most famous one is the oxidative stress theory. Free radicals and peroxides attack all components of cells, including proteins, lipids, RNA, and DNA. Oxidative damage occurs in various aging-associated disease pathologies, especially the cardiovascular diseases and neurological diseases. Theoretically, antioxidant supplementation should be able to reduce the risk of aging-related diseases. The Mediterranean diet with red wine, fruits, vegetables, and other plant foods has been shown to have cardiovascular protection against oxidative damage. At present, the extraction of biological antioxidants from plants is becoming one of the hot topics in the field of medical chemistry.

Polygonum multiflorum Thunb. (何首乌, he-shou-wu) (Figures 1(a) and 1(b)) is a traditional Chinese medicinal plant. As early as 973 A.D., it was incorporated into
Kaibao Bencao, an encyclopedia of medical plants edited under an imperial edict of Song Taizu, the first emperor of the Song Dynasty. The plant is processed to product radix Polygoni Multiflori preparata (Figure 1(c)), traditionally taken to increase vitality, improve the health of blood and blood vessels, blacken hair, strengthen bones, nourish the liver and kidney, and prolong life. Currently, Polygonum multiflorum Thunb. is listed in the Chinese Pharmacopoeia, and radix Polygoni Multiflori preparata is widely used for clinically treating of arteriosclerosis, hyperlipidemia, hypercholesterolemia, and diabetes. It is also used in many Chinese medicinal supplements to improve general health.

2,3,5,4'-Tetrahydroxystilbene-2-O- $\beta$-D-glucoside (THSG) (Figure $1(\mathrm{~d})$ ) is the main component of Polygonum multiflorum Thunb., which is used as a standard compound for appraising Polygonum multiflorum Thunb. in the Chinese Pharmacopoeia [1]. THSG belongs to polyhydroxystilbene group. The structure of THSG is similar to that of resveratrol $\left(3,4^{\prime}, 5\right.$-Trihydroxy-trans-stilbene), which is quite well known for its numerous biological activities especially in cardiovascular protection. As a resveratrol analog with glucoside, THSG has been proved to possess strong antioxidant and free radical scavenging activities even much stronger than resveratrol in superoxide anion radical scavenging, hydroxyl 


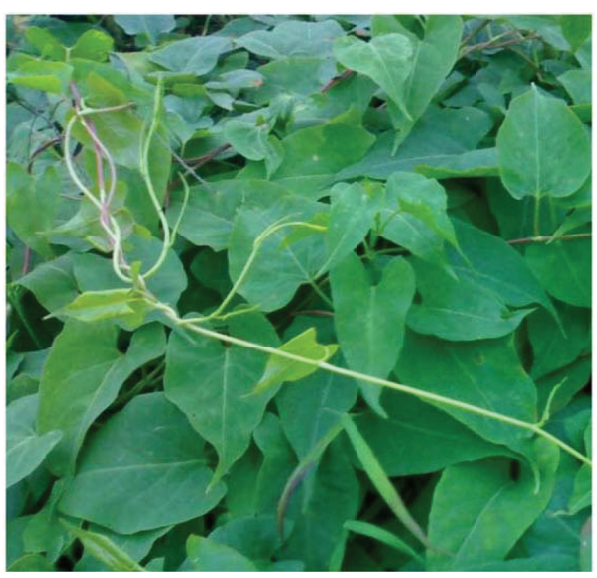

(a)

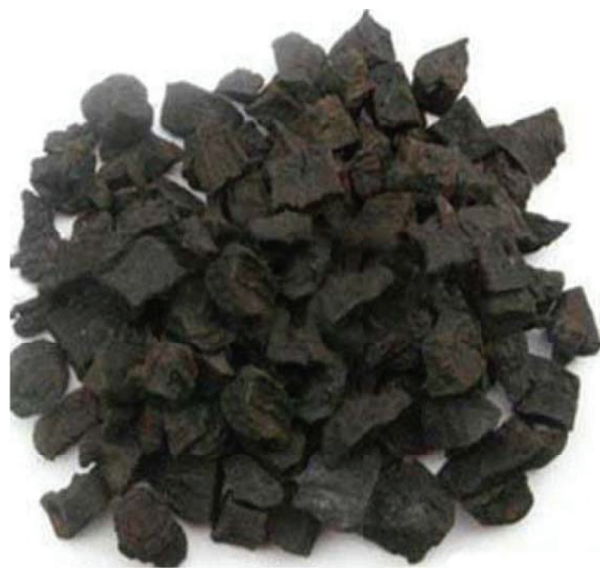

(c)

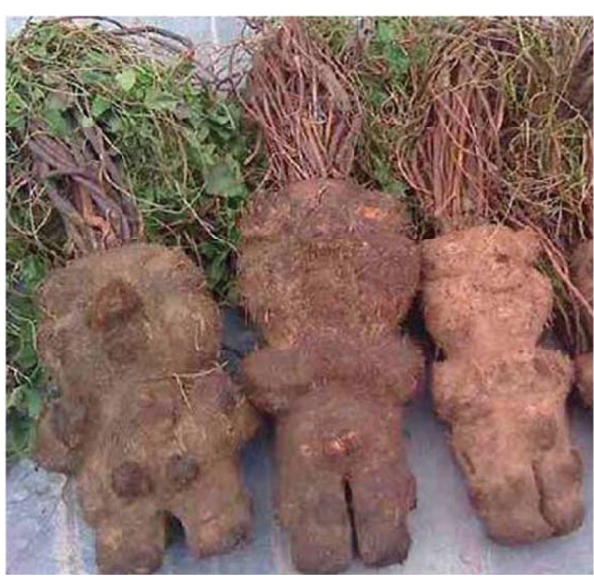

(b)<smiles>OC[C@H]1C[C@H](Oc2c(O)cc(O)cc2/C=C/c2ccc(O)cc2)[C@H](O)[C@@H](O)[C@@H]1O</smiles>

(d)

FIGURE 1: The images of medicinal material Polygonum multiflorum and molecular structure of THSG. (a) Seedling herbs, (b) harvested herbs, (c) processed herbs, radix Polygoni Multiflori preparata, and (d) chemical structure of THSG.

radical scavenging, and DPPH radical scavenging [2]. It is because THSG has a 2-O-Glu group in chemical structure, in which $\mathrm{C}_{5}-\mathrm{OH}$ and $\mathrm{C}_{4}^{\prime}-\mathrm{OH}$ are more active to $\mathrm{H}$-abstraction [3]. Furthermore, 2-O-Glu group can stabilize the phenoxyl free radicals and they are easy to be hydrolyzed in extreme $\mathrm{pH}$ environments (in the gastrointestinal environment).

Contemporary pharmacological studies have demonstrated that THSG exhibits numerous biological functions in antiaging and antiaging-related disease treatments. In this review, we focus on THSG, discussing its biological effects and molecular mechanisms.

\section{Delaying the Senescence Effect}

A few years ago, we found that THSG can delay vascular senescence and markedly enhance blood flow in spontaneously hypertensive rats (SHRs), but it does not affect blood pressure or body weight [4]. The data revealed that senescence-associated $\beta$-galactosidase (SA- $\beta$-gal) staining, $\gamma \mathrm{H} 2 \mathrm{AX}$ phosphorylation, and $\mathrm{p} 53$ acetylation are suppressed by THSG in the aortic arches of SHRs. THSG promotes deacetylation of $\mathrm{p} 53$, a transcription factor associated with aging. THSG also induces endothelial nitric oxide synthase (eNOS) expression in the aortas and urinary mononitrogen oxide $\left(\mathrm{NO}_{x}\right)$ production. In vitro, THSG activates SIRT1 activity, stimulates eNOS promoter reporter gene activity, and ameliorates $\mathrm{H}_{2} \mathrm{O}_{2}$-induced human umbilical vein endothelial cell (HUVEC) senescence [4]. Our unpublished data show that in vivo THSG is more effective in delaying vascular senescence than resveratrol.

A recent study revealed that THSG prolongs the lifespan of senescence-accelerated prone mouse (SAMP8) by $17 \%$ and notably improves their memory. THSG also increase neural klotho protein level and reduce levels of the neural insulin, the insulin receptors, insulin-like growth factor-1 (IGF-1), and IGF-1 receptor in the brain of SAMP8 [5]. In a subsequent report, this research group again demonstrated that THSG improves memory, reduces levels of reactive oxygen species (ROS), nitric oxide (NO), and IGF1 , and increases protein levels of superoxide dismutase (SOD) and klotho in serum. Furthermore, THSG upregulates klotho protein expression in cerebrum, heart, kidney, testis, and epididymis tissues of D-galactose induced aging mice [6]. 
A German study reported that THSG exerted a DAF16-independent antiaging effect in a Caenorhabditis elegans model [7]. THSG prolongs the mean, median, and maximum adult lifespans of $C$. elegans by $23.5 \%, 29.4 \%$, and $7.2 \%$, respectively, and increases the resistance of $C$. elegans to lethal thermal stress, comparable to the effects of resveratrol. THSG also exerts a higher antioxidative capacity in nematode compared with resveratrol and reduces the levels of the aging pigment lipofuscin.

\section{Cardiovascular Protection}

3.1. Atherosclerosis and Lipid Metabolism. An experimental investigation using New Zealand rabbits demonstrated that THSG reduces atherosclerotic plaque accumulation caused by a high cholesterol diet, and lower plasma cholesterol, low-density lipoprotein (LDL) cholesterol, very-lowdensity lipoprotein (VLDL) cholesterol, and triglyceride levels [8]. Moreover, THSG decreases secretion protein levels of the intercellular adhesion molecule- (ICAM-) 1 and the vascular endothelial growth factor (VEGF) in the U937 foam cell cultured medium [8]. Subsequent studies have reported that in rat aortic walls in high-cholesterol-fed rats THSG improves the serum lipid profile and suppresses serum C-reactive protein (CRP), IL- 6 and TNF- $\alpha$ levels, and matrix metalloproteinase(MMP-) 2, MMP-9 mRNA, and protein expressions [9]. THSG also restores the mRNA and protein expression of eNOS in the rat aorta and improves acetylcholine-induced endothelium-dependent relaxation [10]. THSG exhibited antioxidant properties and protected against apoptosis in a lysophosphatidylcholine- (LPC-) induced endothelial cell injury model [11]. THSG suppresses intracellular ROS and malondialdehyde (MDA) and restores SOD and glutathione peroxidase (GSH-Px) levels. THSG apparently reversed the loss of mitochondrial membrane potential, the activation of caspase- 3 and poly(ADP-ribose) polymerase 1 (PARP-1), the decrease of $\mathrm{Bcl}-2$, the upregulation of $\mathrm{Bax}$, and the release of cytochrome C in LPC-stimulated HUVECs [11].

Ten years ago, a Japanese group found that THSG does not affect the food intake, growth, or blood pressure of SHRs, consistent with our data $[4,12]$, but significantly reduces free fatty acid content in serum. THSG significantly reduces cholesterol and neutral lipid content in the VLDL fraction and neutral lipid content in the high-density lipoprotein (HDL) fraction in the blood, as well as neutral lipid content in the liver [12]. Another study reported that THSG administration to rats for 1 week can effectively control serum levels of total cholesterol and LDL cholesterol. The expression of LDL receptors in the liver was significantly upregulated in a high-fat-fed rat model [13]. Furthermore, in vitro experiments revealed a downregulation effect of THSG on 3-hydroxy-3-methylglutaryl-coenzyme A (HMG-CoA) reductase and an upregulation effect on cholesterol 7 alphahydroxylase (CYP7A) in human steatosis L02 cells. THSG enhanced downregulation activities in TC, LDL cholesterol, and VLDL contents and increased activity in HDL cholesterol [14].
3.2. Vascular Remodeling and Fibrosis. In vitro, THSG prevents the proliferation of vascular smooth muscle cells (VSMCs) and blocks the G1/S phase progression of the cell cycle in platelet-derived growth factor-BB- (PDGF-BB-) or angiotensin II-induced VSMCs $[15,16]$. THSG inhibits the phosphorylation of $\mathrm{Rb}$ and extracellular signal-regulated kinase 1/2 (ERK1/2); it also inhibits the expressions of cyclin D1, cyclin-dependent kinase-4 (CDK4), CDK2, cyclin E, the proliferating cell nuclear antigen (PCNA) in PDGF-BBinduced VSMCs [15], phosphorylated ERK1/2, MEK1/2, Src, c-fos, c-jun, and c-myc mRNA in angiotensin II-induced VSMCs [16]. In vivo, THSG inhibits neointimal hyperplasia in a rat carotid arterial balloon injury model [17], and the ratio of intima-to-media was significantly reduced, and the expressions of PCNA, $\alpha$-smooth muscle actin ( $\alpha$-SMA), and PDGF-BB were suppressed. Moreover, signaling pathways associated with smooth muscle cell proliferation, migration, and inflammation were inhibited, in addition to the activation of $\mathrm{AKT}, \mathrm{ERK} 1 / 2$, and nuclear factor $\kappa \mathrm{B}(\mathrm{NF}-\kappa \mathrm{B})$ and the expressions of c-myc, c-fos, c-jun, MMP-2, MMP-9, and collagens I and III [17]. Our recent study reported that orally administering THSG for 14 weeks significantly inhibited vascular remodeling and fibrosis in SHRs with increasing blood flow and with constant blood pressure [18]. THSG reduces intima-media thickness in the aortic arch of SHRs, increases the vascular diastolic rate in response to acetylcholine, and reduces remodeling and fibrosis-related mRNA expression, such as that of genes ACTA2, CCL3, COL1A2, COL3A1, TIMP1 WISP2, IGFBP1, ECE1, KLF5, MYL1 BMP4, FN1, and the plasminogen activator inhibitor-1 (PAI-1). THSG inhibits the acetylation of Smad 3 and prevents Smad3 binding to the PAI1 proximal promoter in SHR aortas [18].

3.3. Heart. THSG improves cardiac ischemia-reperfusion, cardiac remodeling, and cardiac stem cells. The infarct size, ST segment recovery, and incidence of arrhythmia in the THSG postconditioning group are all significantly improved compared with the control group [19]. THSG has also been shown to promote mitochondrial biogenesis and induce the expression of erythropoietin (EPO) in nonhematopoietic cells, including primary cardiomyocytes, and enhance EPOEPO receptor autocrine activity. THSG robustly increases the endurance performance activity of healthy and doxorubicininduced cardiomyopathic mice in ischemic disorders, stimulates myocardial mitochondrial biogenesis, and improves cardiac function [20].

In cardiac remodeling, THSG can attenuate pressure overload-induced cardiac pathological changes. Such pathological changes include increases in heart weight/body weight and left ventricular weight/body weight ratios, increased myocyte cross-sectional areas and left ventricular posterior wall, hypertrophic ventricular septum, and accumulation of myocardial interstitial perivascular collagen, as well as elevated cardiac hydroxyproline content [21]. Furthermore, THSG significantly reduces myocardium angiotensin II, enhances the activities of SOD and GSH-Px in serum and myocardial tissue, and inhibits the protein expression of transforming growth factor beta 1 (TGF- $\beta 1$ ) and the phosphorylation of ERK1/2 and p38 MAP kinase in myocardial 
tissue [22]. However, THSG treatment increases the percentage of the S-phase in sorted c-kit(+) rat cardiac stem cells and promotes expressions of PCNA, VEGF, the Tbox transcription factor, hyperpolarization-activated cyclic nucleotide-gated 2 (HCN2), HCN4, the $\alpha$ myosin heavy chain, $\beta$ myosin heavy chain mRNA, stem cell antigen 1, cardiac troponin-I, GATA-4, Nkx2.5, and connexin 43 protein [22].

3.4. Platelets. In vitro, THSG treatment inhibits adenosine diphosphate- (ADP-) or thrombin-induced platelet aggregation dose-dependently. THSG does not affect intracellular calcium ion dynamics at rest; however, in the ADP or thrombin stimulation, THSG reduces dose-dependently the rise in intracellular calcium flow [23]. Another study demonstrated that THSG prevents dose-dependently collagen-induced platelet aggregation and ATP secretion [24]. THSG also inhibits platelet P-selectin expression, glycoprotein IIb-IIIa binding, and platelet spreading on immobilized fibrinogen, as well as Fc receptor Fc $\gamma$ RIIa, Akt (Ser473), and GSK3 $\beta$ (Ser9) phosphorylations [24].

\section{Neuroprotective Effects}

4.1. Learning and Memory. In $\beta$-amyloid peptide-induced dementia mice, ischemia-reperfusion gerbils, and D-galactose induced dementia mouse models, oral administration of THSG for dementia prevention or treatment improves learning and memory function in Morris water maze tests. THSG significantly decreases MDA level and monoamine oxidase $B$ activity in the cerebral cortex, reduces the affinity of NMDA receptors with ${ }^{3} \mathrm{H}-\mathrm{MK} 801$, and increases expression of nerve growth factor (NGF) and neurotrophic factor-3 in the hippocampal CA1 region [25-27]. Moreover, THSG promotes the differentiation of $\mathrm{PC1} 2$ cells, increases the intracellular calcium level in hippocampal neurons, and facilitates highfrequency stimulation-induced hippocampal long-term potentiation (LTP) in a bell-shaped manner. The facilitation of LTP induction by THSG required calcium/calmodulindependent protein kinase II and ERK activation [28]. In vivo, THSG treatment also restores memory impairment, as assessed using the passive avoidance test, in models for sleep-deprived mice, amyloid- $\beta$-injected aging mice, and kainic acid-injected brain-damage mice. Concurrently, THSG induces expressions of erythropoietin, PPAR- $\gamma$ coactivator $1 \alpha$ (PGC- $1 \alpha$ ), and hemoglobin in astrocytes and $\mathrm{PC} 12$ neuronal-like cells and in the hippocampus of mice [29].

4.2. Neuroinflammation. Neuroinflammation is closely implicated in the pathogenesis of neurological diseases. Thus, the inhibition of microglial inflammation may have potential therapeutic significance for neurological diseases. Researchers have used a microglia BV2 cell line as a model to investigate the antineuroinflammatory effects of THSG, finding that THSG reduced the LPS-induced microglia-derived release of proinflammatory factors such as TNF- $\alpha$, IL- $1 \beta$, IL- 6 , and NO and attenuated LPS-induced nicotinamide adenine dinucleotide phosphate oxidase activation and subsequent ROS production [30, 31]. THSG failed to suppress $\mathrm{I} \kappa \mathrm{B}-\alpha$ degradation, $\mathrm{NF}-\kappa \mathrm{B}$ phosphorylation and nuclear translocation, and ERK1/2, JNK, and p38 phosphorylation. However, THSG markedly reduced the binding of NF- $\kappa$ B to its DNA element in the iNOS promoter [31]. Moreover, THSG stimulates the secretion of the glial cell-line derived neurotrophic factor and the secretion of brain-derived neurotrophic factor and NGF in cultured rat primary astroglial cells, by activating the ERK1/2 pathway [32].

4.3. Alzheimer and Parkinson Diseases. In chronic aluminum exposure or amyloid- $\beta\left({ }_{1-42}\right)$-injected rat models, THSG improves cognitive impairment evaluated using passive avoidance task or Morris water maze tests. THSG reverses the rise in amyloid precursor protein (APP) expression and the downregulation in Src and NR2B mRNA and protein levels in the rat hippocampus $[33,34]$. In APP transgenic mouse models, THSG also reverses the increase in $\alpha$-synuclein expression and aggregation in the hippocampus at the late stage of transgenic mice [35].

In 1-methyl-4-phenyl-1,2,3,6-tetrahydropyridine-treated C57BL/6 mouse models of Parkinson disease, THSG protects dopaminergic neurons from degradation in substantia nigra tyrosine hydroxylase-positive cells, enhances striatal dopaminergic transporter protein levels, and increases striatal Akt and GSK3 $\beta$ phosphorylation and the upregulation of the Bcl-2/BAD ratio. Furthermore, in the pole test, THSG reduces the times required to turn the body and climbing down to the floor [36]. In vitro, THSG protects PC12 cells and SH-SY5Y cells against MPP+-induced neurotoxicity. The antiapoptotic effects of THSG were probably mediated through the inhibition of ROS generation and modulation of JNK activation [37, 38], involving activation of PI3K-Akt pathway [39].

4.4. Cerebral Ischemia. Previous studies have shown that THSG significantly decreases the percentage of apoptotic cells in injured rat brain tissue induced by ischemia reperfusion, promotes $\mathrm{Bcl}-2$, and inhibits Bax protein expression in brain tissue [40]. THSG also promotes changes in animal nerve behavior; improves neurological function scores; increases the expression of NGF, growth-associated protein 43, and PKA catalytic subunit proteins; and presents a positive correlation between neurological function scores and determined protein expression [41]. In the middle cerebral artery occlusion (MCAO) models, THSG significantly reduces the brain infarct volume and the number of apoptosis cells in the cerebral cortex according to a TUNEL assay [42]. Furthermore, the authors used an in vitro ischemic model of oxygen-glucose deprivation followed by reperfusion (OGD-R), revealing that THSG reverses intracellular ROS generation and mitochondrial membrane potential dissipation and inhibits c-Jun N-terminal kinase (JNK) and Bcl2 family-related apoptotic signaling pathway. Concurrently, THSG prevents the expression of iNOS induced by OGD$\mathrm{R}$ through the activation of SIRT1 and inhibition of NF- $\kappa \mathrm{B}$ [42]. 


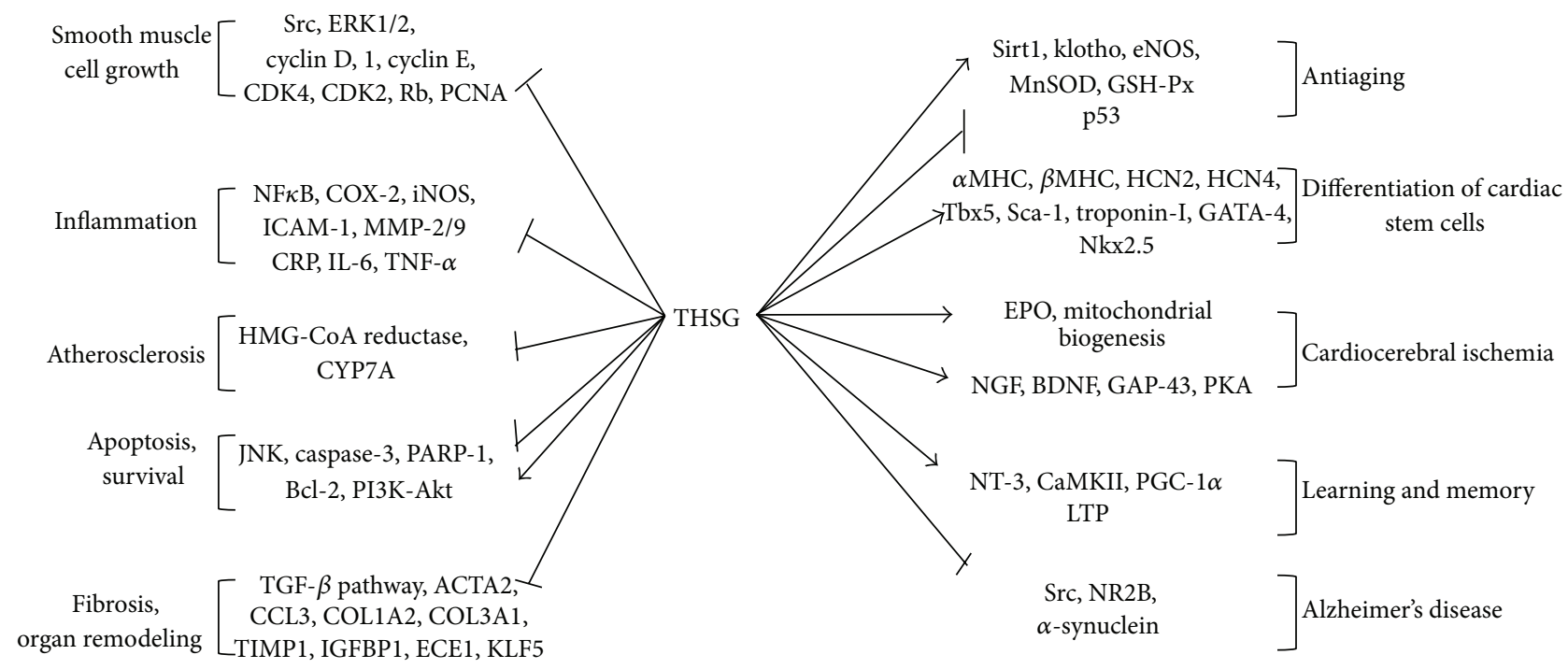

FIGURE 2: The signal transduction pathways regulated by THSG in the antiaging and aging-related diseases. THSG displays different activities in blocking and activating signaling and gene expression in vitro and in vivo.

\section{Diabetes and Other Diseases}

5.1. Diabetes. The beneficial effects of THSG in alleviating diabetic complications are reflected in diabetic nephropathy and gastrointestinal disorders. Treatment with THSG reduces the increase in total cholesterol and triglyceride levels of diabetic rats [43]. Treatment with THSG also significantly reduces blood urea nitrogen, creatinine, 24 hours urinary protein levels, the ratio of kidney weight/body weight, and MDA and markedly increases the activities of SOD and GSH-Px in diabetic rats. Furthermore, THSG inhibits diabetes-induced expression of TGF- $\beta 1$ and cyclooxygenase2 and restores the reduction of SIRT1 expression in diabetic nephropathy [43]. For disorders of gastrointestinal function in diabetes, long-term preventive treatment with THSG relieves delayed gastric emptying and increases intestinal transit, impaired nonadrenergic-noncholinergic relaxations, and deficiency of neuronal NO synthase expression in streptozotocin-induced diabetic mice. Moreover, THSG prevented significant decreases in PPAR- $\gamma$ and SIRT1 expression in diabetic ileum [44].

5.2. Bone Mineral Density. Recently, a study reported that THSG promotes bone mineral density and bone strength in the femoral bones of rats and enhances the bone mineral weight and bone mineral size in the iliac and humeral section after 90 days of administration [45]. Another report described in greater detail how in vitro THSG significantly enhances the cell survival, alkaline phosphatase (ALP) activity, and calcium deposition in $\mathrm{H}_{2} \mathrm{O}_{2}$-injured osteoblastic MC3T3-E1 cells. THSG enhances mRNA expressions of ALP, collagen I, and osteocalcin but weakens the receptor activator of nuclear factor- $\kappa \mathrm{B}$ ligand and IL-6, as well as intracellular ROS and MDA production [46].

5.3. Hair Growth. A report indicated that a THSG fed group had significantly more hair growth compared with the control group, and that THSG accelerated the growth rate of early hair in C57BL/6J mice. In vitro, THSG also promoted hair growth in the cultured tentacles follicles of mice, with longer hair than that in the control group after 8 days [47]. Another report indicated that in vitro THSG increased the proliferation of dermal papilla cells of mice compared with the control group [48]. In addition, THSG promoted tyrosinase activity and melanin biosynthesis dosedependently $[49,50]$.

\section{Summary}

Although THSG has been found to exhibit many medicinal properties, because no systematic study has investigated its regulatory mechanisms and proteomics or genomics data, its functional targets remain unclear. Nevertheless, we summed up the signal transduction pathways that are regulated by THSG, shown in Figure 2, which presents multipathway multitarget characteristics that block and activate different signaling and gene expression. In all the animal experiments in this study, the rats and mice were the main models (Table 1). However, the experiments involving the genetic model and the specific gene knockout model were used less. Most experimental drug dosages of THSG are between 20 and $120 \mathrm{mg} / \mathrm{kg}$, with some individual extreme doses of $300 \mathrm{mg} / \mathrm{kg}$ or more. In most studies, THSG has been administered daily by oral gavage, but in some cases it has been delivered by intraperitoneal injection. The pharmacologic activity of THSH in low concentration in cellular studies is summarized in this review (Table 2). Dosages of THSG in vitro are normally between 0.1 and $100 \mu \mathrm{mol} / \mathrm{L}$, whilst in some dosages the concentration will reach a maximum of $300 \mu \mathrm{mol} / \mathrm{L}$. Then the high concentration of THSG may play a role in toxicological effects instead of activation effects. Because of this, clinical value may be restricted.

From the perspective of drug effects, THSG achieves favorable results in delaying senescence and in treating 


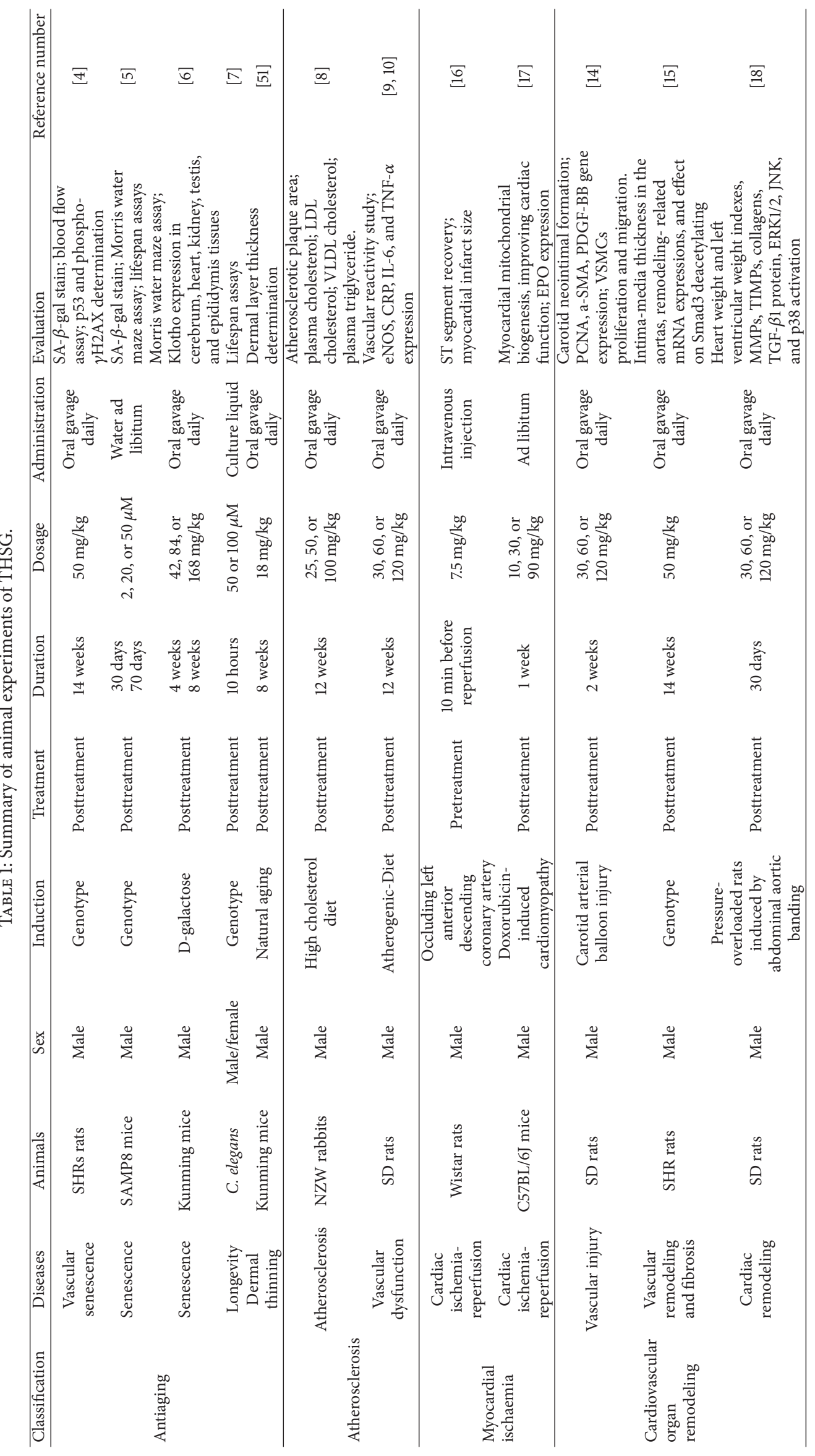




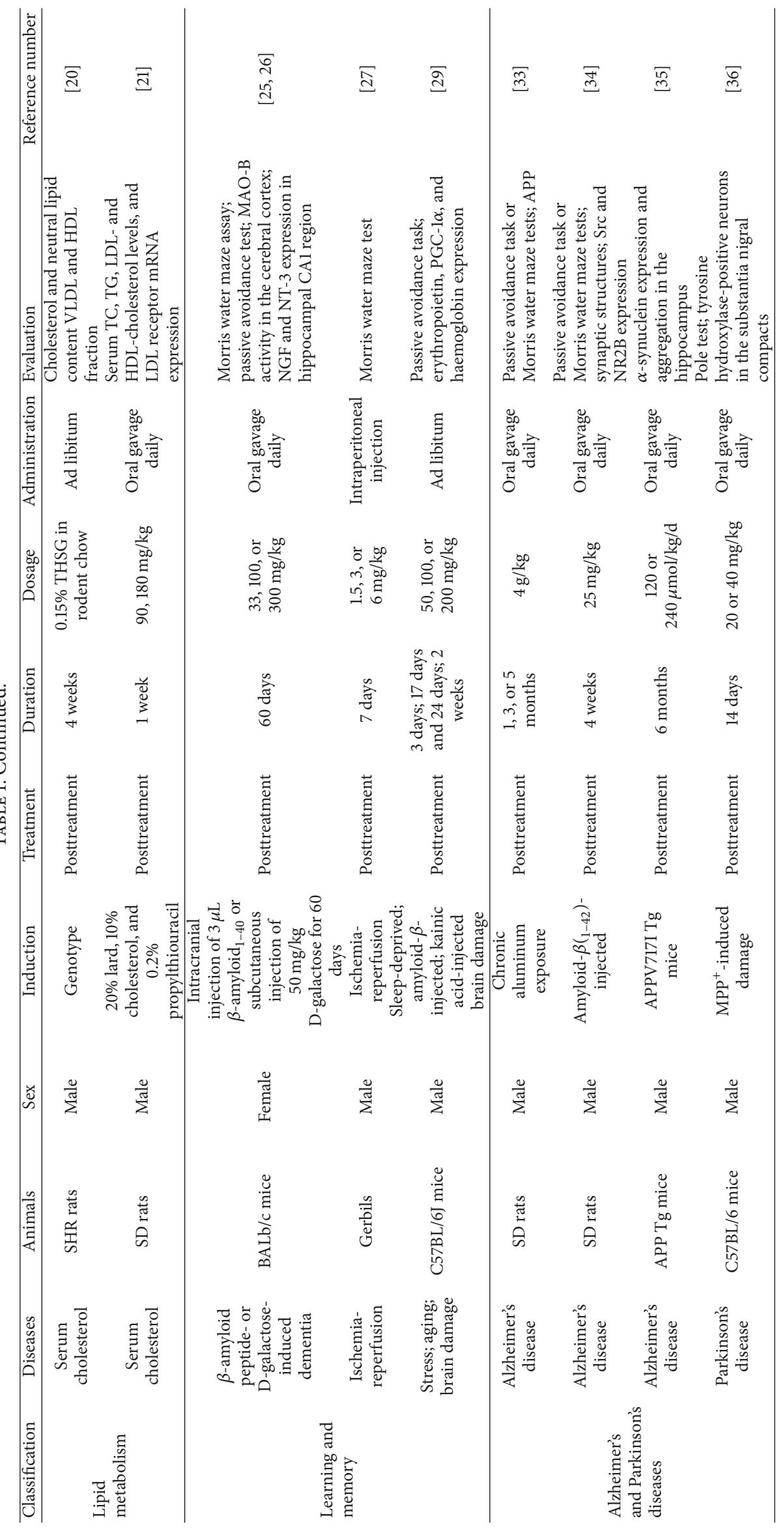




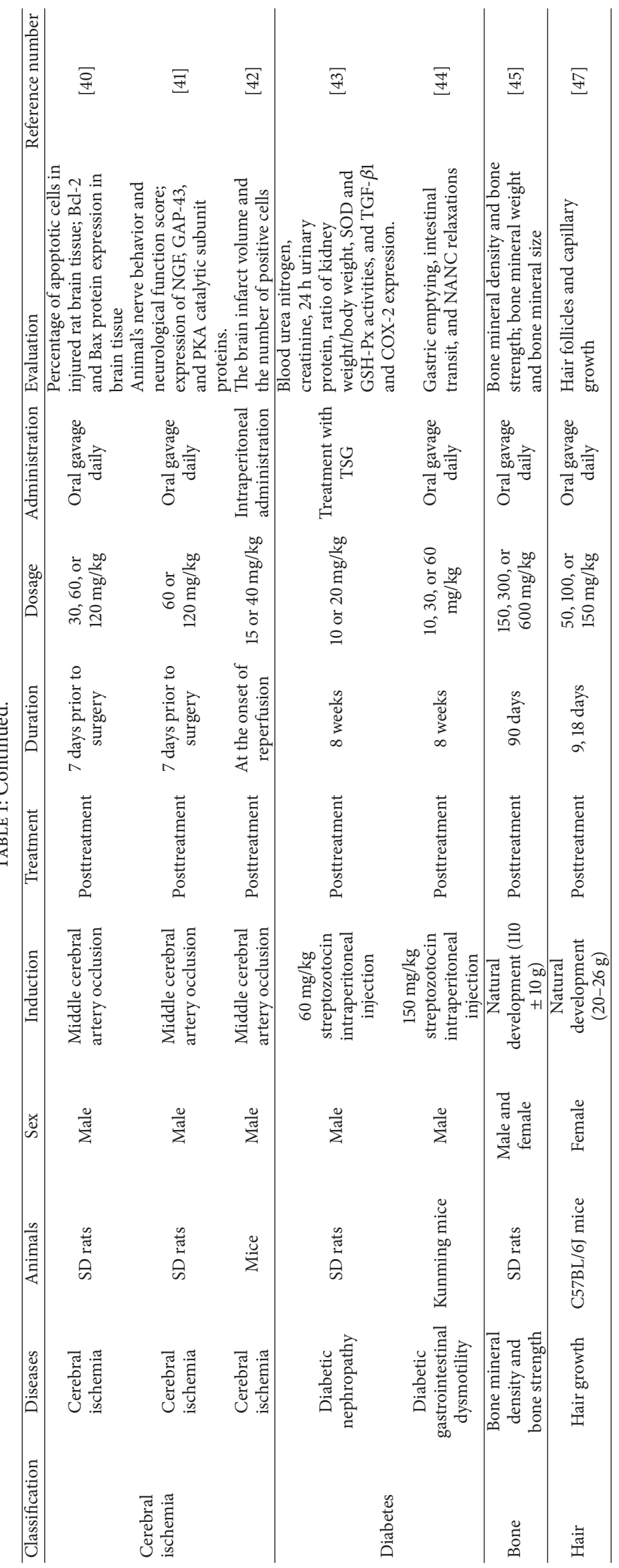




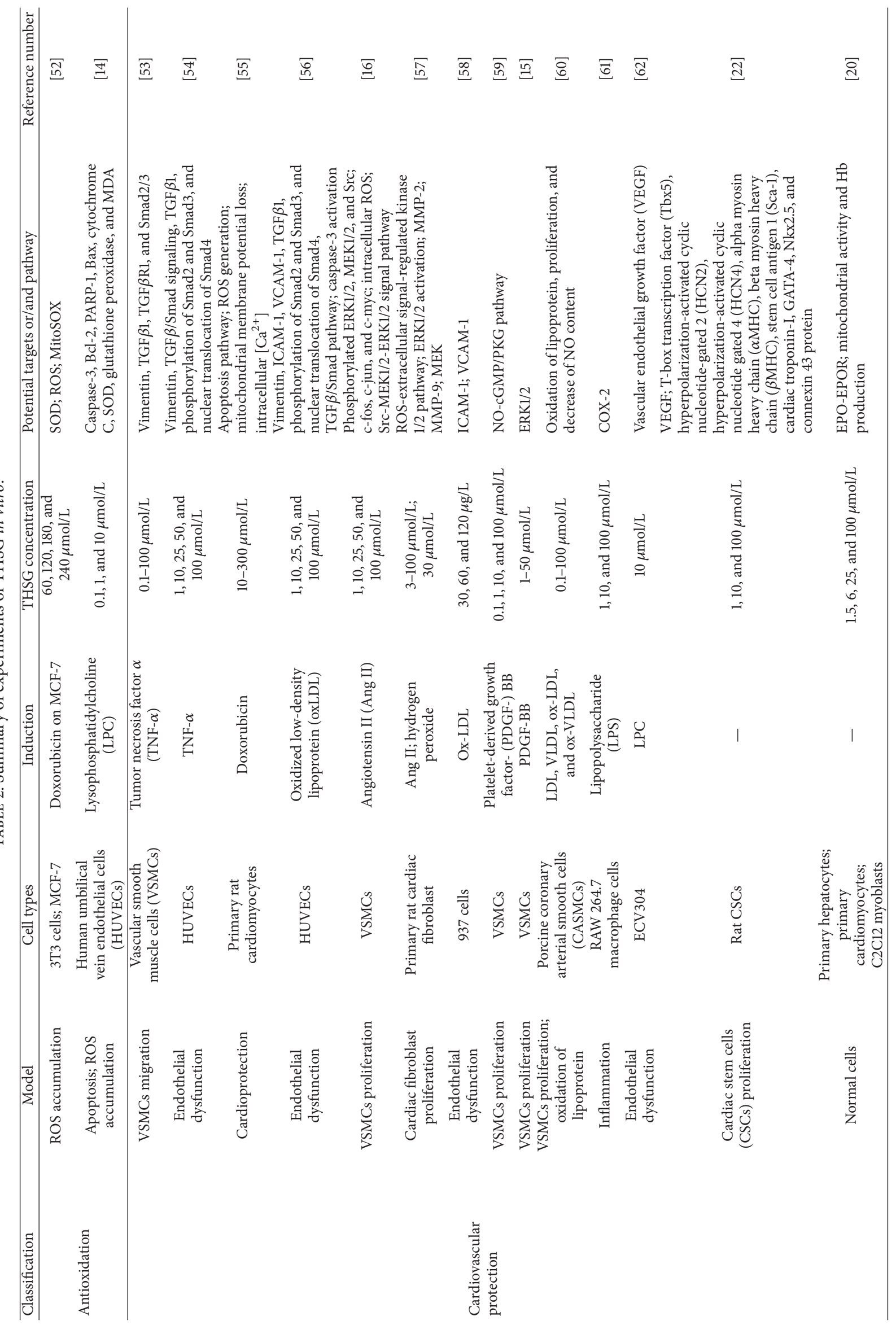




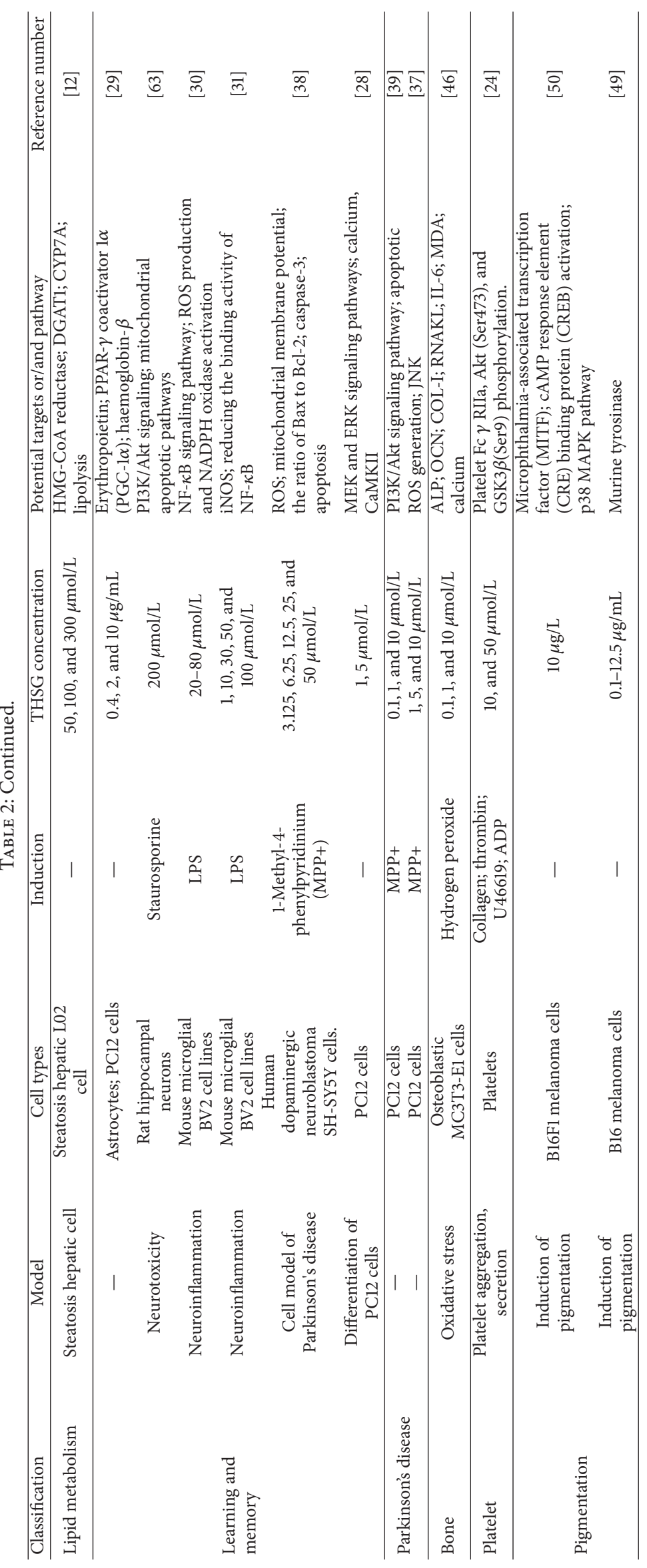


aging-related diseases, especially in the cardiovascular and nervous system. Some studies have shown that THSG may be more effective than resveratrol in delaying senescence. Nevertheless, more research is necessary to explain the mechanism of THSG.

\section{Abbreviations}

\begin{tabular}{|c|c|}
\hline ADP: & Adenosine diphosphate \\
\hline ALP: & Alkaline phosphatase \\
\hline Ang II: & Angiotensin II \\
\hline APP: & Amyloid precursor protein \\
\hline BDNF: & Brain-derived neurotrophic factor \\
\hline CaMKII: & $\begin{array}{l}\text { Calcium/calmodulin-dependent } \\
\text { protein kinase II }\end{array}$ \\
\hline CASMC: & Coronary arterial smooth cell \\
\hline CDK: & Cyclin-dependent kinases \\
\hline COX-2: & Cyclooxygenase-2 \\
\hline CRP: & C-reactive protein \\
\hline CYP7A: & Cholesterol 7 alpha-hydroxylase \\
\hline CSC: & Cardiac stem cells \\
\hline DAF-16: & $\begin{array}{l}\text { A homologous protein of Forkhead box } \\
\text { protein O in C. elegans }\end{array}$ \\
\hline DAT: & Dopaminergic transporter \\
\hline eNOS: & Endothelial NO synthase \\
\hline EPO: & Erythropoietin \\
\hline ERK1/2: & Extracellular signal-regulated kinase $1 / 2$ \\
\hline GAP-43: & Growth associated protein 43 \\
\hline GDNF: & $\begin{array}{l}\text { Glial cell-line derived neurotrophic } \\
\text { factor }\end{array}$ \\
\hline GPIIb-IIIa/PAC-1: & Glycoprotein IIb/IIIa \\
\hline GSH-Px: & Glutathione peroxidase \\
\hline HCN2: & $\begin{array}{l}\text { Hyperpolarization-activated cyclic } \\
\text { nucleotide-gated } 2\end{array}$ \\
\hline HDL: & High-density lipoprotein \\
\hline$\gamma \mathrm{H} 2 \mathrm{AX}:$ & $\begin{array}{l}\text { Histone } \mathrm{H} 2 \mathrm{AX} \text { phosphorylated on } \\
\text { serine } 139\end{array}$ \\
\hline HMG-CoA: & $\begin{array}{l}\text { 3-Hydroxy-3-methylglutaryl-coenzyme } \\
\text { A }\end{array}$ \\
\hline HUVECs: & Human umbilical vein endothelial cells \\
\hline ICAM-1: & Intercellular adhesion molecule-1 \\
\hline IGF-1: & Insulin-like growth factor-1 \\
\hline iNOS: & Inducible NO synthase \\
\hline JNK: & c-Jun N-terminal kinase \\
\hline LDL: & Low-density lipoprotein \\
\hline LTP: & Long-term potentiation \\
\hline LPC: & Lysophosphatidylcholine \\
\hline LPS: & Lipopolysaccharide \\
\hline MAO-B: & Monoamine oxidase B \\
\hline MCAO: & Cerebral artery occlusion \\
\hline MDA: & Malondialdehyde \\
\hline MMP: & Matrix metalloproteinase \\
\hline MPO: & Myeloperoxidase \\
\hline MPP+: & 1-Methyl-4-phenylpyridinium ion \\
\hline MPTP: & $\begin{array}{l}\text { Ethyl-4-phenyl-1,2,3,6- } \\
\text { tetrahydropyridine }\end{array}$ \\
\hline NADPH: & $\begin{array}{l}\text { Nicotinamide adenine dinucleotide } \\
\text { phosphate }\end{array}$ \\
\hline
\end{tabular}

NANC relaxation: Nonadrenergic-noncholinergic relaxation

NF-kappaB: $\quad$ Nuclear factor $\kappa \mathrm{B}$

NGF: Nerve growth factor

nNOS: $\quad$ Neuronal NO synthase

NO: $\quad$ Nitric oxide

$\mathrm{NO}_{x}: \quad \quad$ Nitric oxide and nitrogen dioxide (NO and $\mathrm{NO}_{2}$ )

NT-3: $\quad$ Neurotrophic factor-3

OGD-R: Oxygen-glucose deprivation followed

PAI-1: $\quad$ Plasminogen activator inhibitor-1

PARP-1: $\quad$ Poly(ADP-ribose) polymerase 1

PCNA: $\quad$ Proliferating cell nuclear antigen

PDGF-BB: $\quad$ Platelet-derived growth factor-BB

PGC- $1 \alpha$ : $\quad$ PPAR- $\gamma$ coactivator $1 \alpha$

PLC: $\quad$ Lysophosphatidylcholine

PPAR- $\gamma$ : $\quad$ Peroxisome proliferator activated receptor gamma

RANKL: $\quad$ Receptor activator of nuclear factor- $\kappa$ B ligand

ROS: $\quad$ Reactive oxygen species

SA- $\beta$-gal: $\quad$ Senescence-associated $\beta$-galactosidase

SAMP8: $\quad$ Senescence-accelerated prone mouse

$\alpha$-SMA: $\quad \alpha$-smooth muscle actin

SOD: $\quad$ Superoxide dismutase

Tbx5: $\quad$ T-box transcription factor

THSG: $\quad 2,3,5,4^{\prime}$-Tetrahydroxystilbene-2-O- $\beta$-Dglucoside

TGF- $\beta 1$ : $\quad$ Transforming growth factor beta 1

TNF- $\alpha$ : $\quad$ Tumor necrosis factor $\alpha$

TUNEL assay: Terminal deoxynucleotidyl transferase mediated dUTP nick end labeling assay

VCAM-1: $\quad$ Vascular cell adhesion molecule 1

VEGF: Vascular endothelial growth factor

VLDL: $\quad$ Very-low-density lipoprotein

VSMCs: $\quad$ Vascular smooth muscle cells.

\section{Competing Interests}

The authors declare that they have no competing interests.

\section{Acknowledgments}

This work was supported by grants from the Specialized Research Fund for the National Natural Science Foundation of China (81274130), the National Natural Science Foundation of China Youth Fund (81102532), the Doctoral Program of Higher Education of China (20113107110006), and the Shanghai 085 Project of Higher Education Connotation Construction (085ZY1202).

\section{References}

[1] Pharmacopoeia Commission of the Ministry of Health of the People's Republic of China, Pharmacopoeia of the People's Republic of China (2010 edition, in Chinese), China Medical Science and Technology Press, Beijing, China, 2010. 
[2] L.-S. Lv, "Study on stilbene from roots of Polygonum multiglorum Thunb. antioxidant activities in vitro," Food Science, vol. 28, no. 1, pp. 313-317, 2007.

[3] L.-S. Lv, H. Chi-Tang, and J. Tang, "Structure-activity relationship of stilbene glycoside from Polygonum multiflorum Thunb. and resveratrol," Food \& Machinery, vol. 25, no. 5, pp. 57-58, 2009.

[4] X. Han, S. Ling, W. Gan, L. Sun, J. Duan, and J.-W. Xu, " $2,3,5,4^{\prime}$ Tetrahydroxystilbene-2-O- $\beta$-d-glucoside ameliorates vascular senescence and improves blood flow involving a mechanism of p53 deacetylation," Atherosclerosis, vol. 225, no. 1, pp. 76-82, 2012.

[5] X. Zhou, Q. Yang, Y. Xie et al., “Tetrahydroxystilbene glucoside extends mouse life span via upregulating neural klotho and downregulating neural insulin or insulin-like growth factor 1," Neurobiology of Aging, vol. 36, no. 3, pp. 1462-1470, 2015.

[6] X.-X. Zhou, Q. Yang, Y.-H. Xie et al., "Protective effect of tetrahydroxystilbene glucoside against $\mathrm{D}$-galactose induced aging process in mice," Phytochemistry Letters, vol. 6, no. 3, pp. 372-378, 2013.

[7] C. Büchter, L. Zhao, S. Havermann et al., “TSG $\left(2,3,5,4^{\prime}\right.$ tetrahydroxystilbene-2-O- $\beta$-D-glucoside) from the Chinese Herb Polygonum multiflorum increases life span and stress resistance of caenorhabditis elegans," Oxidative Medicine and Cellular Longevity, vol. 2015, Article ID 124357, 12 pages, 2015.

[8] P.-Y. Yang, M. R. Almofti, L. Lu et al., "Reduction of atherosclerosis in cholesterol-fed rabbits and decrease of expressions of intracellular adhesion molecule- 1 and vascular endothelial growth factor in foam cells by a water-soluble fraction of Polygonum multiflorum," Journal of Pharmacological Sciences, vol. 99, no. 3, pp. 294-300, 2005.

[9] W. Zhang, C.-H. Wang, F. Li, and W.-Z. Zhu, "2,3,4" ,5Tetrahydroxystilbene-2-O- $\beta$-D-glucoside suppresses matrix met-alloproteinase expression and inflammation in atherosclerotic rats," Clinical and Experimental Pharmacology and Physiology, vol. 35, no. 3, pp. 310-316, 2008.

[10] M. Nakatsuka, H. Ogawa, K. Yamamoto, and K. Baba, "Effects of tetrahydroxystilbene glucoside from Polygonum multiflorum Thunb on lipid metabolism in spontaneously hypertensive rats," in Proceedings of the Pharmaceutical Society of Japan 126th Annual Meeting, Abstract 31-0691, 2006 (Japanese).

[11] X. Gao, Y. Hu, and L. Fu, "Blood lipid-regulation of stilbene glycoside from Polyonum mulyiflorum," Zhongguo Zhong Yao Za Zhi, vol. 32, pp. 323-326, 2007 (Chinese).

[12] W. Wang, Y. He, P. Lin et al., "In vitro effects of active components of Polygonum Multiflorum Radix on enzymes involved in the lipid metabolism," Journal of Ethnopharmacology, vol. 153, no. 3, pp. 763-770, 2014.

[13] W. Zhang, X.-L. Xu, Y.-Q. Wang, C.-H. Wang, and W.-Z. Zhu, "Effects of 2,3,4',5-tetrahydroxystilbene $2-O-\beta$-D-glucoside on vascular endothelial dysfunction in atherogenic-diet rats," Planta Medica, vol. 75, no. 11, pp. 1209-1214, 2009.

[14] J. Zhao, S. Xu, F. Song, L. Nian, X. Zhou, and S. Wang, "2,3,5,4'Tetrahydroxystilbene-2-O-b-D-glucoside protects human umbilical vein endothelial cells against lysophosphatidylcholineinduced apoptosis by upregulating superoxide dismutase and glutathione peroxidase," IUBMB Life, vol. 66, no. 10, pp. 711-722, 2014.

[15] X.-L. Xu, Y.-J. Huang, Y.-Q. Wang, X.-F. Chen, and W. Zhang, " $2,3,4^{\prime}, 5$-Tetrahydroxystilbene- $2-O-\beta$-D-glucoside inhibits platelet-derived growth factor-induced proliferation of vascular smooth muscle cells by regulating the cell cycle,"
Clinical and Experimental Pharmacology and Physiology, vol. 38, no. 5, pp. 307-313, 2011.

[16] X.-L. Xu, Y.-J. Huang, D.-Y. Ling, and W. Zhang, "Inhibitory effects of 2,3,4/,5-tetrahydroxystilbene-2-O- $\beta$-D-glucoside on angiotensin II-induced proliferation of vascular smooth muscle cells," Chinese Journal of Integrative Medicine, vol. 21, no. 3, pp. 204-210, 2015.

[17] X.-L. Xu, D.-Y. Ling, Q.-Y. Zhu, W.-J. Fan, and W. Zhang, "The effect of $2,3,4^{\prime}, 5$-tetrahydroxystilbene-2-0- $\beta$-D glucoside on neointima formation in a rat artery balloon injury model and its possible mechanisms," European Journal of Pharmacology, vol. 698, no. 1-3, pp. 370-378, 2013.

[18] J. Duan, X. Han, S. Ling et al., "Aortic Remodelling Is Improved by $2,3,5,4 /$-Tetrahydroxystilbene-2-O- $\beta$-D-glucoside involving the smad 3 pathway in spontaneously hypertensive rats," Evidence-Based Complementary and Alternative Medicine, vol. 2015, Article ID 789027, 10 pages, 2015.

[19] S. Ye, L. Tang, J. Xu, Q. Liu, and J. Wang, "Postconditioning's protection of THSG on cardiac ischemia-reperfusion injury and mechanism," Journal of Huazhong University of Science and Technology. Medical Sciences, vol. 26, no. 1, pp. 13-16, 2006.

[20] P.-L. Hsu, L.-Y. Horng, K.-Y. Peng, C.-L. Wu, H.-C. Sung, and R.-T. Wu, "Activation of mitochondrial function and $\mathrm{Hb}$ expression in non-haematopoietic cells by an EPO inducer ameliorates ischaemic diseases in mice," British Journal of Pharmacology, vol. 169, no. 7, pp. 1461-1476, 2013.

[21] X. L. Xu, Q. Y. Zhu, C. Zhao et al., "The effect of 2,3,4',5tetrahydroxystilbene-2-O- $\beta$-D-glucoside on pressure overloadinduced cardiac remodeling in rats and its possible mechanism," Planta Medica, vol. 80, no. 2-3, pp. 130-138, 2014.

[22] F. Song, J. Zhao, F. Hua et al., "Proliferation of rat cardiac stem cells is induced by $2,3,5,4^{\prime}$-tetrahydroxystilbene-2-O- $\beta$-Dglucoside in vitro," Life Sciences, vol. 132, pp. 68-76, 2015.

[23] Y. Zhang, L. Yang, and J. Wu, "Effect of 2,3,5,4'-tetrahydroxystilbene-2-O- $\beta$-D-glucoside on platelet aggregation and cytosolic free calcium concentration," Yi Yao Dao Bao, vol. 29, pp. 1120-1122, 2010 (Chinese).

[24] K. Xiang, G. Liu, Y.-J. Zhou et al., “2,3,5,4'-tetrahydroxystilbene-2-O- $\beta$-D-glucoside (THSG) attenuates human platelet aggregation, secretion and spreading in vitro," Thrombosis Research, vol. 133, no. 2, pp. 211-217, 2014.

[25] J. Chu, C. Ye, and L. Li, "Effects of stilbene glycoside on learning and memory function and free radicals metabolism in dementia model mice," Zhongguo Kang Fu Li Lun He Shi Jian, vol. 9, pp. 643-645, 2003 (Chinese).

[26] J. Chu, C. Ye, L. Li, and L. Zhang, "Effects of stilbene-glycoside on learning and memory ability and neurotrophic factor of brain aging model mice induced by D-galactose," Zhongguo Yao Fang, vol. 16, pp. 13-16, 2005 (Chinese).

[27] Z. Liu, L. Li, C. Ye, and Y. Wang, "Effects of tetrahydroxystilbene glucoside on learning and memory ability and NMDA-receptor binding to [3H] MK801 in forebrain of ischemia-reperfusion gerbils," Zhongguo Xin Yao Za Zhi, vol. 13, pp. 223-226, 2004 (Chinese).

[28] T. Wang, Y.-J. Yang, P.-F. Wu et al., “Tetrahydroxystilbene glucoside, a plant-derived cognitive enhancer, promotes hippocampal synaptic plasticity," European Journal of Pharmacology, vol. 650, no. 1, pp. 206-214, 2011.

[29] L.-Y. Horng, P.-L. Hsu, L.-W. Chen et al., "Activating mitochondrial function and haemoglobin expression with EH-201, an inducer of erythropoietin in neuronal cells, reverses memory 
impairment," British Journal of Pharmacology, vol. 172, no. 19, pp. 4741-4756, 2015.

[30] F. Zhang, Y.-Y. Wang, J. Yang, Y.-F. Lu, J. Liu, and J.-S. Shi, "Tetrahydroxystilbene glucoside attenuates neuroinflammation through the inhibition of microglia activation," Oxidative Medicine and Cellular Longevity, vol. 2013, Article ID 680545, 8 pages, 2013.

[31] C. Huang, Y. Wang, J. Wang, W. Yao, X. Chen, and W. Zhang, "TSG $(2,3,4$ ', 5 -tetrahydroxystilbene 2 -O- $\beta$-D-glucoside) suppresses induction of pro-inflammatory factors by attenuating the binding activity of nuclear factor- $\kappa \mathrm{B}$ in microglia," Journal of Neuroinflammation, vol. 10, article 129, 2013.

[32] F. Lin, Y. Zhou, W. Shi, Y. Wan, Z. Zhang, and F. Zhang, "Tetrahydroxystilbene glucoside improves neurotrophic factors release in cultured astroglia," CNS \& Neurological DisordersDrug Targets, vol. 15, no. 4, pp. 514-519, 2016.

[33] H.-B. Luo, J.-S. Yang, X.-Q. Shi, X.-F. Fu, and Q.-D. Yang, "Tetrahydroxy stilbene glucoside reduces the cognitive impairment and overexpression of amyloid precursor protein induced by aluminum exposure," Neuroscience Bulletin, vol. 25, no. 6, pp. 391-396, 2009.

[34] L. Zhou, Y. Hou, Q. Yang et al., "Tetrahydroxystilbene glucoside improves the learning and memory of amyloid- $\beta_{1-42}$-injected rats and may be connected to synaptic changes in the hippocampus," Canadian Journal of Physiology and Pharmacology, vol. 90, no. 11, pp. 1446-1455, 2012.

[35] L. Zhang, S. Yu, R. Zhang, Y. Xing, Y. Li, and L. Li, “Tetrahydroxystilbene glucoside antagonizes age-related $\alpha$-synuclein overexpression in the hippocampus of APP transgenic mouse model of Alzheimer's disease," Restorative Neurology and Neuroscience, vol. 31, no. 1, pp. 41-52, 2013.

[36] L. Zhang, L. Huang, L. Chen, D. Hao, and J. Chen, "Neuroprotection by tetrahydroxystilbene glucoside in the MPTP mouse model of Parkinson's disease," Toxicology Letters, vol. 222, no. 2, pp. 155-163, 2013.

[37] X. Li, Y. Li, J. Chen et al., "Tetrahydroxystilbene glucoside attenuates $\mathrm{MPP}+$-induced apoptosis in PC12 cells by inhibiting ROS generation and modulating JNK activation," Neuroscience Letters, vol. 483, no. 1, pp. 1-5, 2010.

[38] F.-L. Sun, L. Zhang, R.-Y. Zhang, and L. Li, “Tetrahydroxystilbene glucoside protects human neuroblastoma SH-SY5Y cells against $\mathrm{MPP}^{+}$-induced cytotoxicity," European Journal of Pharmacology, vol. 660, no. 2-3, pp. 283-290, 2011.

[39] R. Qin, X. Li, G. Li et al., "Protection by tetrahydroxystilbene glucoside against neurotoxicity induced by $\mathrm{MPP}^{+}$: the involvement of PI3K/Akt pathway activation," Toxicology Letters, vol. 202, no. 1, pp. 1-7, 2011.

[40] L. Zhao, C. Li, L. Zhang, W. Cui, and L. Li, "Effect of tetrahydroxystilbene glucoside on cell apoptosis is in focal cerebral ischemia rats," Zhong Cao Yao, vol. 39, pp. 394-397, 2008 (Chinese).

[41] J. Yang, Z. Zhou, Q. Yang, L. Zheng, and J. Zeng, "Neuroprotective mechanism of tetrahydroxystilbene glucoside on rats after cerebral ischemia-reperfusion," Zhong Nan Da Xue Xue Bao Yi Xue Ban, vol. 35, no. 4, pp. 321-328, 2010 (Chinese).

[42] T. Wang, J. Gu, P.-F. Wu et al., "Protection by tetrahydroxystilbene glucoside against cerebral ischemia: involvement of JNK, SIRT1, and NF- $\kappa$ B pathways and inhibition of intracellular ROS/RNS generation," Free Radical Biology and Medicine, vol. 47, no. 3, pp. 229-240, 2009.

[43] C. Li, F. Cai, Y. Yang et al., "Tetrahydroxystilbene glucoside ameliorates diabetic nephropathy in rats: involvement of SIRT1 and TGF- $\beta 1$ pathway," European Journal of Pharmacology, vol. 649, no. 1-3, pp. 382-389, 2010.

[44] M.-J. Chang, J.-H. Xiao, Y. Wang, Y.-L. Yan, J. Yang, and J.-L. Wang, "2, 3, 5, 4/-Tetrahydroxystilbene-2-O-beta-D-glucoside improves gastrointestinal motility disorders in STZ-induced diabetic mice," PLoS ONE, vol. 7, no. 12, article e50291, 2012.

[45] X. Hu, J. Zhuo, G. Liu, and R. Xie, "Effect of stilbene glycoside on bone mineral density and bone strength of rats," Zhong Yi Xue Bao, vol. 26, pp. 696-698, 2011 (Chinese).

[46] J.-K. Zhang, L. Yang, G.-L. Meng et al., "Protective effect of tetrahydroxystilbene glucoside against hydrogen peroxideinduced dysfunction and oxidative stress in osteoblastic MC3T3-E1 cells," European Journal of Pharmacology, vol. 689, no. 1-3, pp. 31-37, 2012.

[47] Z. Yan, Y. Yong, and W. Licheng, "The effect of stilbene to growth cycle hair in C57B1/6J mouse," Zhe Jiang Yi Xue Jiao Yu, vol. 12, pp. 38-41, 2013.

[48] Y. N. Sun, L. Cui, W. Li et al., "Promotion effect of constituents from the root of Polygonum multiflorum on hair growth," Bioorganic and Medicinal Chemistry Letters, vol. 23, no. 17, pp. 4801-4805, 2013.

[49] S. Guan, W. Su, N. Wang, P. Li, and Y. Wang, "A potent tyrosinase activator from radix polygoni multiflori and its melanogenesis stimulatory effect in B16 melanoma cells," Phytotherapy Research, vol. 22, no. 5, pp. 660-663, 2008.

[50] Z. Jiang, J. Xu, M. Long, Z. Tu, G. Yang, and G. He, “2, 3, $5,4^{\prime}$-tetrahydroxystilbene-2-O- $\beta$-D-glucoside (THSG) induces melanogenesis in B16 cells by MAP kinase activation and tyrosinase upregulation," Life Sciences, vol. 85, no. 9-10, pp. 345350, 2009.

[51] X. Zhou, L. Ge, Q. Yang et al., “Thinning of dermas with the increasing age may be against by tetrahydroxystilbene glucoside in mice," International Journal of Clinical and Experimental Medicine, vol. 7, no. 8, pp. 2017-2024, 2014.

[52] M.-T. Sheu, H.-J. Jhan, C.-M. Hsieh, C.-J. Wang, and H.-O. Ho, "Efficacy of antioxidants as a complementary and alternative medicine (CAM) in combination with the chemotherapeutic agent doxorubicin," Integrative Cancer Therapies, vol. 14, no. 2, pp. 184-195, 2015.

[53] W. Yao, Q. Sun, L. Huang et al., “Tetrahydroxystilbene glucoside inhibits TNF- $\alpha$-induced migration of vascular smooth muscle cells via suppression of vimentin," Canadian Journal of Physiology and Pharmacology, vol. 94, no. 2, 2016.

[54] W. Yao, C. Gu, H. Shao et al., "Tetrahydroxystilbene glucoside improves TNF- $\alpha$-induced endothelial dysfunction: involvement of TGF $\beta /$ smad pathway and inhibition of vimentin expression," American Journal of Chinese Medicine, vol. 43, no. 1, pp. 183-198, 2015.

[55] S.-H. Zhang, W.-Q. Wang, and J.-L. Wang, "Protective effect of tetrahydroxystilbene glucoside on cardiotoxicity induced by doxorubicin in vitro and in vivo," Acta Pharmacologica Sinica, vol. 30, no. 11, pp. 1479-1487, 2009.

[56] W. Yao, C. Huang, Q. Sun, X. Jing, H. Wang, and W. Zhang, "Tetrahydroxystilbene glucoside protects against oxidized LDL-induced endothelial dysfunction via regulating vimentin cytoskeleton and its colocalization with ICAM-1 and VCAM-1," Cellular Physiology and Biochemistry, vol. 34, no. 5, pp. 1442-1454, 2014.

[57] W. Zhang, X.-F. Chen, Y.-J. Huang, Q.-Q. Chen, Y.-J. Bao, and W. Zhu, "2,3,4I,5-Tetrahydroxystilbene-2-O- $\beta$-d-glucoside inhibits angiotensin II-induced cardiac fibroblast proliferation 
via suppression of the reactive oxygen species-extracellular signal-regulated kinase 1/2 pathway," Clinical and Experimental Pharmacology and Physiology, vol. 39, no. 5, pp. 429-437, 2012.

[58] Y.-Q. Wang, Y. Shen, F. Li, C.-H. Wang, and W. Zhang, " $2,3,4^{\prime}$,5Tetrahydroxystilbene-2-O- $\beta$-D-glucoside suppresses expression of adhesion molecules in aortic wall of dietary atherosclerotic rats and promonocytic U937 cells," Cell Biochemistry and Biophysics, vol. 67, no. 3, pp. 997-1004, 2013.

[59] X.-L. Xu, Y.-J. Huang, X.-F. Chen, D.-Y. Lin, and W. Zhang, "2,3,4/,5-Tetrahydroxystilbene-2-O- $\beta$-d-glucoside inhibits proliferation of vascular smooth muscle cells: involvement of $\mathrm{NO} /$ cGMP/PKG pathway," Phytotherapy Research, vol. 26, no. 7, pp. 1068-1074, 2012.

[60] Q.-L. Liu, J.-H. Xiao, R. Ma, Y. Ban, and J.-L. Wang, "Effect of 2,3,5,4'-tetrahydroxystilbene-2-O-beta-D-glucoside on lipoprotein oxidation and proliferation of coronary arterial smooth cells," Journal of Asian Natural Products Research, vol. 9, no. 8, pp. 689-697, 2007.

[61] Y.-Z. Zhang, J.-F. Shen, J.-Y. Xu, J.-H. Xiao, and J.-L. Wang, "Inhibitory effects of 2,3,5,4/-tetrahydroxystilbene-2-O- $\beta$-Dglucoside on experimental inflammation and cyclooxygenase 2 activity," Journal of Asian Natural Products Research, vol. 9, no. 4, pp. 355-363, 2007.

[62] L. Zhang, Y.-C. Rui, Y. Qiu, T.-J. Li, H.-J. Liu, and W.-S. Chen, "Expression of VEGF in endothelial cells and the effects of 2,3,5,4l-tetrahydroxystilbene-2-O- $\beta$-D-glucoside," Yao Xue Xue Bao, vol. 39, no. 6, pp. 406-409, 2004.

[63] X.-P. Yang, T.-Y. Liu, X.-Y. Qin, and L.-C. Yu, "Potential protection of $2,3,5,4^{\prime}$-tetrahydroxystilbene-2-O- $\beta$-D-glucoside against staurosporine-induced toxicity on cultured rat hippocampus neurons," Neuroscience Letters, vol. 576, pp. 79-83, 2014. 


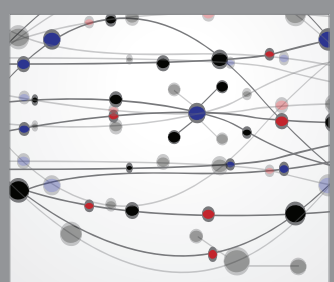

The Scientific World Journal
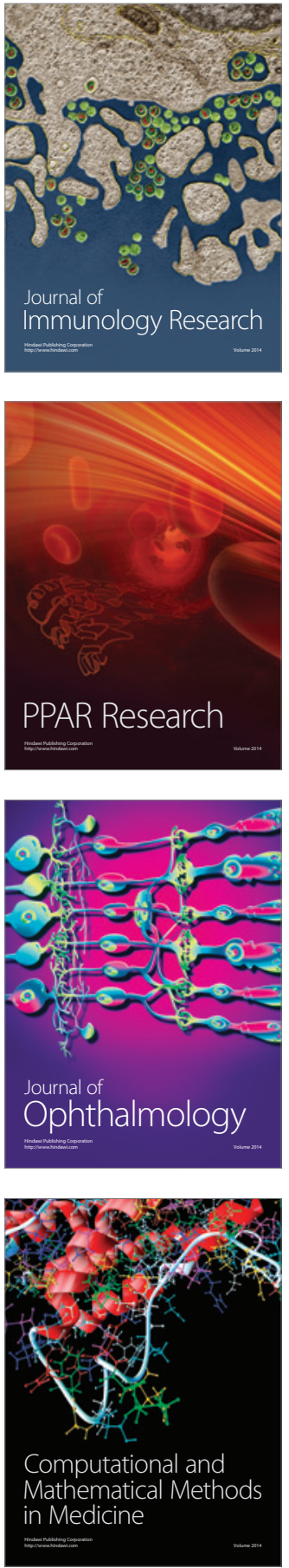

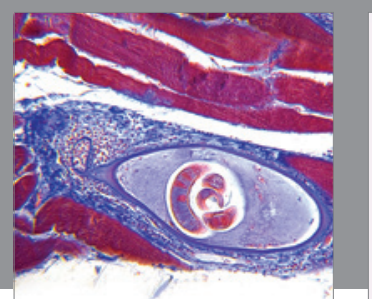

Gastroenterology Research and Practice

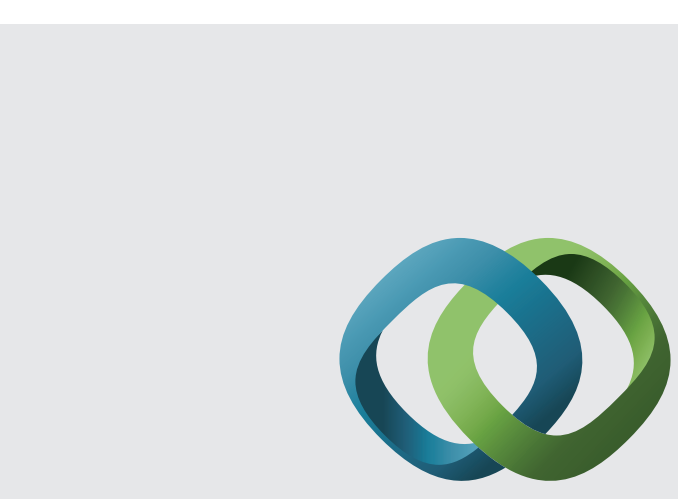

\section{Hindawi}

Submit your manuscripts at

http://www.hindawi.com
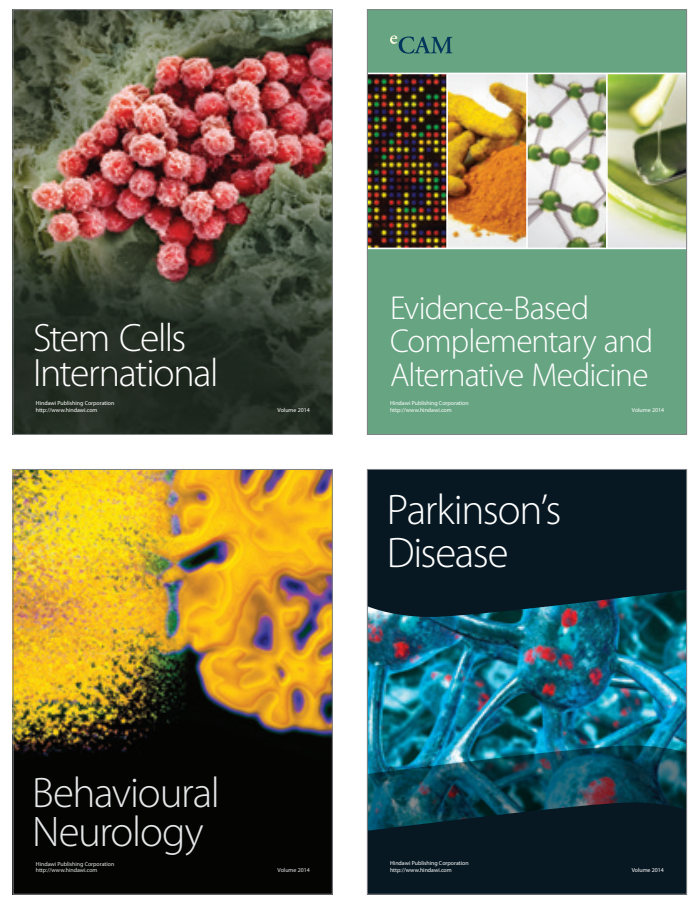
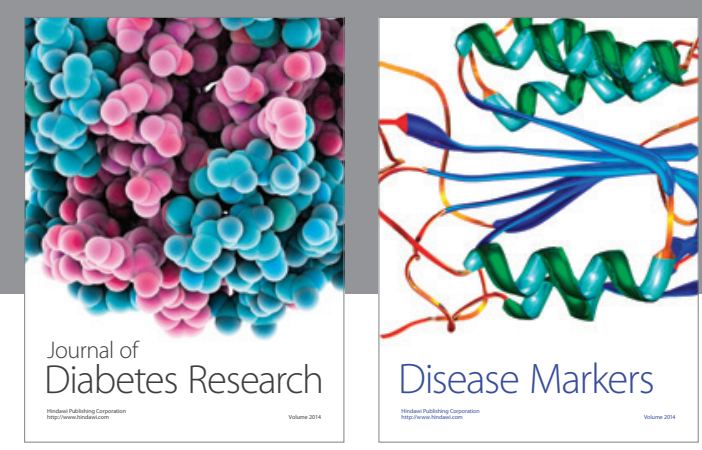

Disease Markers
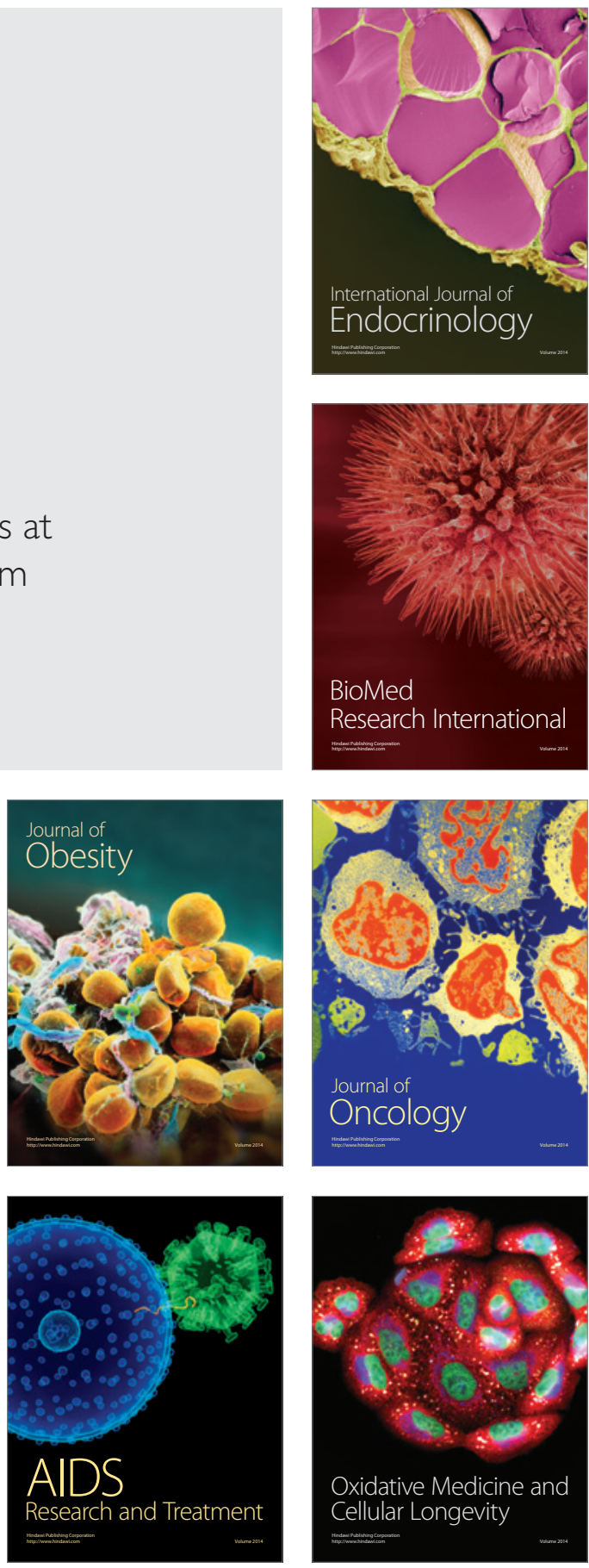